\title{
Modeling for incentive payoffs in the Nigerian construction industry
}

\author{
Amaka Chinweude Ogwueleka and Marthinus Johannes Maritz \\ Department of Construction Economics, \\ University of Pretoria, Pretoria, South Africa
}

\begin{abstract}
Incentives are mechanisms used to create genuine opportunity for contracting parties to work together to achieve good results, rational returns and bear appropriate risks. The question of how to motivate the construction workforce rightly so as to achieve best performance has remained paramount to project owners. This paper investigates on how to model for incentive payoffs in the Nigerian construction industry in order to effectively utilise the benefits of incentive mechanisms. The collected data are analysed using descriptive and inferential statistics, such as frequency counts, charts and principal component analysis. The findings reveal the metrics for measuring organisational incentive payoff and the scaling factor for each metric. The study further develops the employee incentive payoff models for both operational workers and management staff in the construction sector. This study provides a practical solution to the application of incentive mechanisms in construction projects. The paper recommends the need for restructuring of incentive mechanisms to significantly impact on other performance criteria therefore contributing to best performance in project delivery.
\end{abstract}

Keywords: incentive payoffs, performance improvement, partnering, alliance contracting and Nigerian construction industry

\subsection{Introduction}

Contracting has become an important avenue for service delivery. Researchers and project practitioners have sought for various ways to outsource goods and services in order to improve project performance. The use of performance-based contracting systems has been overwhelming whereby contractors are rewarded for good performance and penalised for failing to achieve project outcomes (Smith and Grinker, 2003; Martin, 2007). Regardless of this practice, clients are often concerned with obtaining best performance from contractors within reasonable prices by stating the objectives and specifying the scope and metrics for achieving the project goals with less emphasis on how they are to be achieved. Most limitations associated with project delivery are centered on improper alignment of contractors' objectives with clients' expectations. Partnering was introduced in the late 1980's to facilitate an environment of trust where contracting parties can share a lot of objectives (Tang et al., 2006). The priorities of contracting parties are different; therefore the use of partnering alone cannot promote good performance but might create a platform that is prone to recurring disputes (Hosie, 2001).

Researchers have advocated the need of a formal agreement which can promote mutual understanding, effective knowledge sharing and good working relationships amongst contracting parties (Popp and Zenger, 2002; Vlaar et al., 2006). The use of incentives in contracts has allowed for effective sharing of resources, risks and profits/losses measured against the performance indicators amongst contracting parties based on the contract agreement. Incentives encourage contracting parties to work together in a mutual agreement in order to achieve good results, make rational returns and bear appropriate risks (Tang et al., 2007). Most project managers are faced with the challenge on how to effectively incorporate incentives in their projects to motivate construction employees rightly (Maritz and Ogwueleka, 2013). The study conducted by Bubshait (2003) compares the perceptions of clients and contractors regarding the use of incentives. The study lacks empirical data for assessing the performance outcomes of incentive projects. Bower et al. (2002) assess the impact of quality incentives in project alliancing but the study failed to analyse the relationship existing between quality 
incentives and quality outcomes. A further study conducted by Jansson and Ryddoke (2010) assesses the relationship existing between quality incentive and quality outcome only.

Most studies on incentives focus on a single incentive plan (Berends, 2000; Brenen and Marshall, 2000; Rose and Manley, 2010) but the use of a single incentive plan has remained problematic. The use of a single incentive plan does not allow for the weights of performance criteria to be considered which might have a negative effect on project success (Ittnera et al., 2003). Beer et al. (2004) further emphasise that a single incentive plan can cause employees to over invest their efforts in one area at the expense of other areas. There is a need for a study that will consider the weights of performance criteria to assess the effect of incentives in construction projects. In order to bridge this gap, this study adopts the critical-performance criteria (such as: time, cost, quality and safety) to evaluate incentive mechanisms in construction projects. Literature scan reveals that there is little empirical research on the effect of incentive mechanisms on performance in the context of Nigerian construction projects. In Nigeria, there are two existing studies conducted Olugbenga (2011) and Abdulsalam et al. (2012) on incentive schemes in the construction industry. Both studies investigated on the types of incentive schemes used in the construction industry only but failed to provide empirical data for assessing their impact of project improvement. The study conducted by Ogwueleka (2015) reveals that there is no formal existing scheme for incentivising construction workforce in the Nigerian construction industry.

This paper advances the existing body of knowledge by modeling for incentive payoffs in the Nigerian construction industry. In order to achieve this aim, the following objectives are considered: a) to examine the variables influencing employees' efforts towards improved performance in compensation/incentive payoffs; and b) to identify performance objectives for measuring incentive payoffs in Nigerian construction projects.

\subsection{Literature review}

\subsection{The use of incentive mechanisms in project performance}

Incentive projects have experienced more timely and qualitative performance when compared to nonincentive projects (Meng and Gallagher, 2012). Previous studies have advocated incentives as motivational tools which can be used to achieve project outcomes and higher returns (Martin, 2003; Kohlmeyer and Drake, 2008). Incentives are used to promote unified motivation across project teams through improved work relationships. Bonner and Sprinkle (2002) argued that although a positive relationship exists between incentives and performance but the use of incentive does not directly influence performance. Therefore, there is a need to construct incentive plans based on mutual benefits by aligning the objectives of contracting parties. Incentives can be incorporated in performance objectives, such as cost, time, quality and safety in order to achieve the expected outcomes. As previously discussed, the use of a single incentive plan has remained problematic; this is a need for the weights of performance to be considered in the design of incentive schemes. This study advocates the use of a multiple incentives mechanism which is targeted towards motivating contractors to meet or surpass all performance goals, on or before a target date, within or at a target cost and within the specified quality in a healthy environment.

There are basically two attributes involved in incentive schemes which are: a) to align the objectives of the contracting parties through the use of performance measures; and b) to link them to payments. Incentives which are linked to performance measures, other than cost and schedules, should be designed to cover the areas of performance improvement which may include quality, operation, nondisturbance, design integrity, and safety (Lahdenpera and Koppinen, 2003). The use of a quality performance bonus is effectively applied where contractors are offered additional profit for achieving 
the predetermined performance levels (Bower et al., 2002). Operation rewards are used to improve operational performance thereby increasing the chances of achieving the project success. Likewise, an incentive bonus can also be given to the contractor to maintain design integrity, minimise disturbance caused by the project and the risk of accidents and fatalities (safety) on construction sites (Lahdenpera and Koppinen, 2003). The literature scan reveals several parameters influencing the four key performance objectives and they are compiled as performance parameters for this study (Iyer and Jha, 2005; Meeampol and Ogunlana, 2006; Cheung et al., 2013; Wang et al., 2013).

\subsection{Paying for performance in projects}

Performance can be linked to payments by tailoring the acceptance provisions and payments for contract deliverables to performance objectives which may be based on individual, group and organisation or a combination of them. Performance payment can be grouped into two common types, namely:

\section{Merit Pay}

This can be referred to as pay increases or increments where it is either based on the individual pay on performance or a performance-related bonus plus a fixed wage or salary (Bryson et al., 2011). It is usually based on the subjective measures of employee performance where in most cases the assessment lacks workability and effectiveness due to its poor performance appraisal system.

\section{Group Incentives}

They can be categorised into three types namely; gain sharing, profit sharing, and employee stock plans. Gain-sharing is not strictly based on profit rather it can be referred to as a compensation system based on an agreed sharing formula between employees and the employer, which is shared upon an improved performance resulting from productivity gains (De Silva, 2004; Bryson et al., 2011). Profitsharing is a scheme where employees are entitled to a share of profits that may be in cash or otherwise a deferred payment kept, for example, a special fund and share options (De Silva, 2004; Bryson et al., 2011). Employee stock plan involves a scheme where employees are given the opportunity to own shares in the firms in which they work in exchange of performance bonuses (Bryson et al., 2011).

It is important to note that incentives are no longer about getting a cash bonus but rather recognition for a job well done. The recognition is typically used to reward an employee for his/her behaviour or to recognise an employee for exceptional performance and productivity. Incentive schemes can be designed in three different forms namely: financial, semi-financial, and non-financial. Financial incentive schemes are aimed at increasing efficiency by enhancing the motivation of employees to work harder and smarter through the offer of a financial reward in order to attain project goals that are above minimum standards (Rose and Manley, 2005). Semi-financial incentive schemes have the attributes of both financial and non-financial incentives and they are geared towards compensating for jobs that cannot be subjectively measured, classified as those which may have some monetary benefits but not directly linked with the output and wages (Chavan, 2010). Non-financial incentive schemes are indirect rewards made by the management to convey appreciations to employees for completing their tasks effectively and in required manners.

\subsection{Incentive payoffs in the construction industry}

Incentive provisions can be incorporated in a contractual strategy with significant potential to address performance problems. For example, the provision of time incentive for early completion, cost incentive for cost saving, quality incentive for zero or minor defects, safety incentive for complying 
with stricter safety rules and standards and a combination of incentives to make improvements in more than one performance area (Bubshait, 2003). These provisions can be applied to different types of contract arrangements to achieve performance. In fixed-price contracts, incentives are usually given to contractors by specifying a fixed amount of the entire scope of work as payoff. This allows contractors to bear the risks of losses associated with higher expected cost and the benefits associated with cost saving (Berends, 2000). Cost-plus or cost-reimbursable contracts provide a platform for sharing of any difference between the actual cost and the target cost (budget) amongst contracting parties using an agreed proportion where there is any cost under-run or over-run (Broome and Perry, 2002). Likewise, target cost contracts allow for any savings or losses between the initial target cost and the actual cost on project completion to be shared amongst contracting parties using a predetermined share ratio as stated in the contract document (Bower et al., 2002). In performancebased contracts, incentives given to contractors are based on final project outcomes, for example, the realisation of expected standard of reliability and competence (OGC, 2003).

The adoption of an incentive plan to achieve cost efficiency can be measured using cost performance index. The important parameters for calculating cost performance were identified as budgeted cost of work scheduled (planned) and actual cost of work performed (actual) (Lester, 2007). Delay in project completion will create a negative impact on time and cost performances (Ogwueleka, 2011), therefore there is need to adopt parameters measuring time performance for incentive design. Lester (2007) highlights these parameters as original duration planned for the work to date, actual time expected for the work to date, budget cost of work performed (actual), and budgeted cost of work scheduled (actual). Quality performance improvements are required to improve contractors' productivity and profitability as well as clients' expectations. The primary benefits of adopting incentive to meet quality requirements may include less work, higher productivity, lower cost and increased stakeholder satisfaction. Incentive compensation plan is tied to quality metrics used for quantitative assessment of a project's level of quality. Metrics for measuring quality performance are used to assess the project's level of conformity to its established quality baseline while the acceptance criteria are pre-established minimum standards or requirements for acceptance (DHHR, 2006). CBP (2005) emphasises that quality metrics should focus on measuring reworks, defects, defects removal rate, and delivery of quality against specifications. The scorecard approach is commonly used to assess safety system effectiveness in projects and their basic measures include the accident record, the audit score and perception survey results (EHS, 2001).

De Silva (2004) highlights the four main goals of performance compensation as: a) equity amongst beneficiaries, b) efficiency objectives, c) micro-economic stability through high employment levels and low inflation, and d) efficient allocation of the labour market. Performance compensation has increased dramatically as a result of the widespread concern over inefficiencies at workplace and also the belief that it can raise productivity growth and improve profitability (Bryson et al., 2011). Incentive compensation payoffs are adopted in the construction industry at two different levels, namely: the employee and the organisation (Hughes et al. 2007). In an organisation, incentives are targeted to achieve one or more of these project objectives which are time, cost, quality and safety. This study advocates the use of multiple incentives plan that is targeted towards achieving the four project objectives in a particular project. In this scheme, a performance compensation plan is tied to each project objective using the identified most critical parameter to measure the payoff. Fundamentally, performance compensation plans for employees are usually targeted on paying for their inputs rather than the value of their job. The literature scan reveals various variables influencing the assessment employees' inputs towards achieving improved performance and compensations. 
These variables are compiled for assessing an employee's input towards work productivity for compensation/incentive payoffs (Kuykendall, 2007; IRF, 2010; Bei, 2013; Marawar, 2013).

\subsection{Research Methodology}

\subsection{Questionnaire design}

The research problem addressed is that incentives have remained vital motivational tools recommended by different researchers which can be used to motivate the construction workforce to achieve project success. Regardless of this, the use of incentives has failed to achieve best performance in the Nigerian construction industry. This paper focuses on resolving these challenges confronting the use of incentives in construction projects by developing incentive models which pertain to the Nigerian construction industry. This study adopts a quantitative approach in data collection where the survey was carried out using questionnaires which was found effective because of the relative ease of obtaining standard data appropriate for achieving the objectives of this study. A questionnaire survey was used to get information from respondents in order to assess the key objectives of this study. Based on the strengths and weaknesses identified in the literature scan, a draft questionnaire was prepared and shown to professional experts and academics in the field. Amendments were made on the drafted questionnaire based on the suggestions of the reviewers.

\subsection{Characteristics of respondents}

The study population comprises of project stakeholders who are involved in both building and civil engineering works in Abuja zone of Nigeria. Abuja is the Federal capital territory of Nigeria and it is regarded as the most populous city in Nigeria with highest record of construction activities and where most multinational companies have their headquarters as well as construction associations and outfits. For the questionnaire survey, the numerous and unclassified databases prompted the use of nonprobability (purposive) sampling first to identify the sample population (sample frame) and second, the stratified probability (random) was adopted to select the respondents of sample size from the sample frame. Neuman (2006) emphasises that choosing a large sample size alone does not guarantee a representative sample. Saunders et al. (2009) further stipulate that in choosing a sample size, there are three factors to be considered which are: a) the level of certainty that the characteristics of data collected will represent the characteristics of the total population; b) the margin of error that can be tolerated; c) the type of analysis to be used; and d) the size of the population. Based on these recommendations and Yamane's formula (1967), a total number of 338 construction professionals were selected for the study. This sample population includes public sector clients, registered contractors with Federal Ministry of Works and Housing and registered consultants. The survey was carried out from August to October 2014; a total number of 101 valid responses were computed for the data analysis with a response rate of 30 per cent. Waris et al. (2014, citing Dulami et al., 2003) emphasise that the response rates of postal survey in the construction industry are usually within the ranges of 20 to 30 per cent. Thus, the response rate of this survey is good enough to make meaningful analysis and interpretations.

\subsection{Modelling process for incentive payoffs in construction projects}

For the purpose of this study, the research modelling process is performed for organisational incentive payoff and employee incentive payoff. Organisational incentive payoff denotes incentives initiated between the employer and the organisation targeted towards improved performance while employee 
incentive payoff represents the compensation plans used within the organisation to motivate employees.

\subsection{Measures}

The structured questionnaire is classified into three parts; part one focuses on the demographic data of respondents. Part two examines the variables influencing employee's payoffs using a 5-likert scale of $1=$ very low and $5=$ extremely high while part three evaluates the performance metrics in measuring incentive payoffs in construction projects using a 5-likert scale of $1=$ not important and 5=very important.

\subsection{Variables}

There are two categories of variables used for this study in order to achieve the research objectives. The first category represents variables used to assess employees' inputs towards improved performance and the second category is performance indicators/parameters, these are represented as in Table 1.

Table 1: Compiled parameters for performance indicators from the literature scan

\begin{tabular}{ll}
\hline Code & Performance parameters \\
\hline \multicolumn{2}{l}{ Cost performance } \\
PF 1a & Efficient cash flow system \\
PF 1b & Within budget \\
PF 1c & Efficient cost control \\
PF 1d & Measurement \& correction of works \\
PF 1e & Project cost outcome \\
Time performance \\
PF 2a & Timely completion \\
PF 2b & Timeous communication process \\
PF 2c & Reasonable claims for extension of time \\
PF 2d & Adequate schedule process \\
PF 2e & Schedule change control \\
Quality performance \\
PF 3a & Minimise defects \\
PF 3b & Satisfactory quality of work \\
PF 3c & Quality of materials used \\
PF 3d & Effective quality management plan \\
Safety performance \\
PF 4a
\end{tabular}

\subsection{Data analysis}

Demographics of respondents and the variables influencing employee's payoffs are analysed using basic descriptive statistics, such as frequency counts, percentages and charts. Principal component analysis (PCA) is used to select the representative factors of performance indicators from the data set basically, and not to uncover the hidden relationships. Pournara and Wernisch (2007) emphasise that PCA can be used for data reduction by evaluating for the smallest possible set of principal components that can explain most of the variances in the data set. 


\subsection{Sample characteristics}

Table 2 reveals the profile of respondents from questionnaire survey. The analysis shows that the three major aspects of contracting parties are well represented, $15.8 \%$ represents the clients/employers, and $42.6 \%$ of respondents are engaged in consulting firms while $41.6 \%$ of respondents are employed in construction companies. The analysis of job description reveals also that each designation is well represented with a percentage of 36.6 for managerial position, a percentage of 38.6 for middle management position and a percentage of 24.8 for operational staff. From the analysis of respondents' work experience, it shows that $80.2 \%$ of the total respondents have between 1 to 20 years of work experience where $32.7 \%$ of total respondents have between 11 to 20 years of work experience. The analysis of projects participated by respondents reveals that $81.2 \%$ of respondents had participated in numbers of projects ranging from 1 to 20, this implies the majority of them have ample experience that are relevance to achieve the objectives of this study. In terms of academic qualifications, $46.5 \%$ of respondents have obtained formal education in various Bachelor degrees while a combination of more than $80 \%$ of respondents has either Bachelor, Masters or PhD/D.Tech degrees in various disciplines.

Table 2: Profile of respondents from questionnaire survey

\begin{tabular}{lccc}
\hline Demographic information & Frequency & Percentage & Cumulative percentage \\
\hline Organisation type & 16 & 15.8 & 15.8 \\
Clients/employers & 43 & 42.6 & 58.4 \\
Consulting firms & 42 & 41.6 & 100 \\
Construction companies & & & \\
Job description & 37 & 36.6 & 36.6 \\
Managerial position & 39 & 38.6 & 75.2 \\
Middle management position & 25 & 24.8 & 100 \\
Operational (skilled/unskilled) & & & \\
& & & \\
Work experience & 48 & 47.5 & 87.5 \\
1 to 10 years & 33 & 32.7 & 96 \\
11 to 20 years & 16 & 15.8 & 100 \\
21 to 30 years & 4 & 4.0 & \\
Above 30 & & & 30.7 \\
& & & 51.5 \\
Number of participated projects & 31 & 30.7 & 71.3 \\
1 to 5 & 21 & 20.8 & 81.2 \\
to 10 & 20 & 19.8 & 100 \\
21 to 20 & 10 & 9.9 & \\
Above 30 & 19 & 18.8 & 5.9 \\
& & & 18.8 \\
Academic qualification & & 5.9 & 65.3 \\
WAEC & 6 & 12.9 & 100 \\
N.Diploma/H.Diploma & 13 & 46.5 & \\
B.Tech/B.Sc. (honours) & 47 & 30.7 & \\
M.Sc./M.Tech & 31 & 4.0 & \\
PhD/D.Tech. & 4 & & \\
\hline
\end{tabular}




\subsection{Results and interpretation}

\subsection{Variables influencing compensation/incentive payoffs in projects}

This section assesses the most influential variables required to measure employee performance in an organisation. This forms the parameters used in measuring employees' efforts in construction projects and the result of the analysis is presented in Figure 1. According to Jacobsson and Linderoth (2010), mean score of above 3.5 in a scale of 5 can be regarded as high impact. Based on this threshold, "technical efforts", "work output" and "job requirement" are considered highly significant in assessing the performance of operational staff while "technical efforts", "work output" and "managerial skills" are considered highly significant in assessing the performance of management staff.

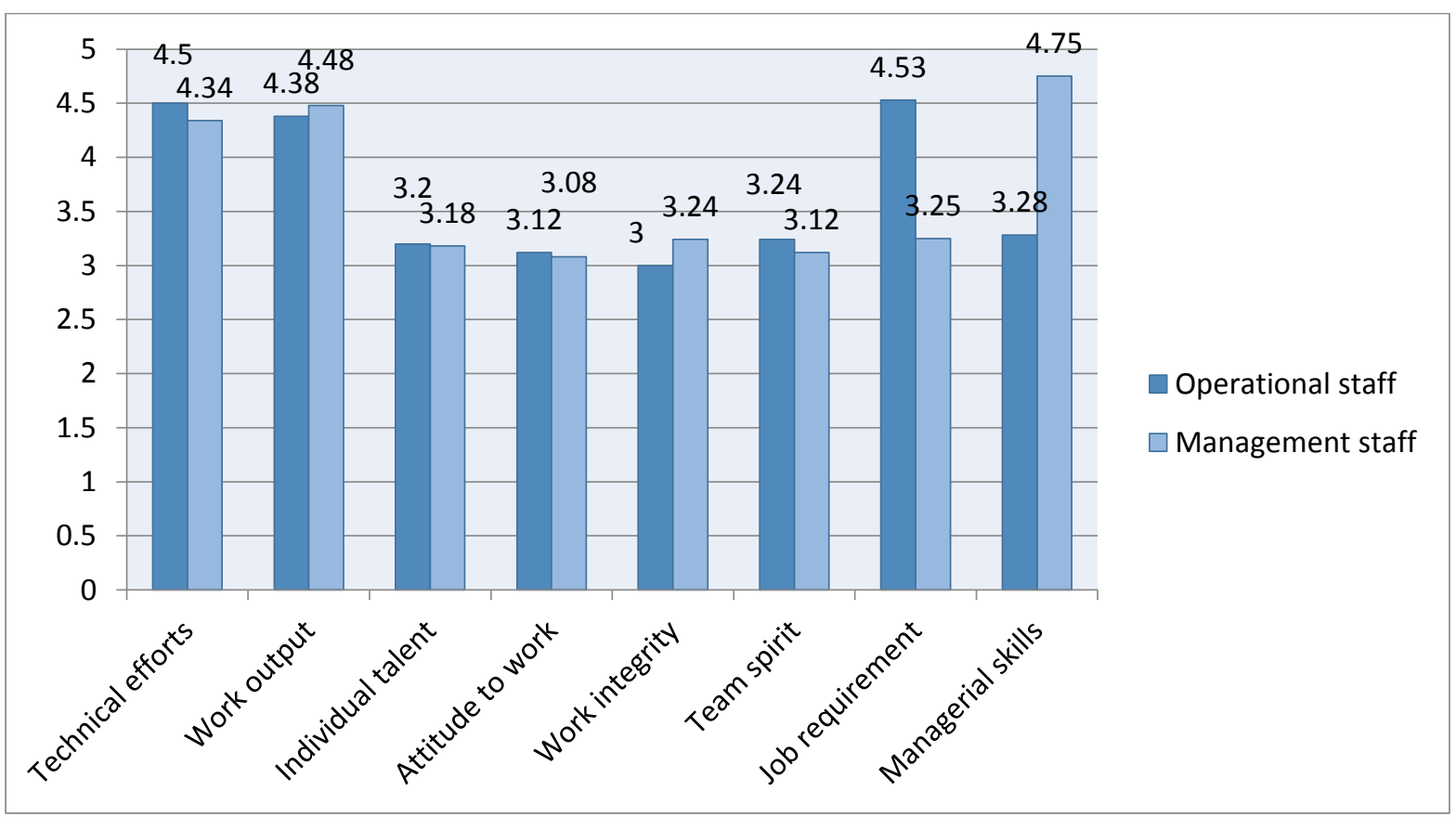

Figure 1: Variables for measuring employee compensation/incentive payoffs

\subsection{Evaluating performance indicators/parameters in construction projects}

As previously noted the purpose of this analysis is to reduce the performance variables measuring the indicators and select a representative variable for each indicator using PCA. Table 3 reveals the eigenvalues of the correlation matrix for performance parameters. Four components are retained for rotation based on the eigenvalue-one criterion, the Scree test, the proportion of variance accounted for and the interpretability criterion. The result of the rotated factor pattern is displayed in Table 4 showing the parameters with high loadings $(>0.40)$. Based on the threshold of communality estimates, factor loadings of below 0.5 are discarded. The final communality estimates of performance parameters range from 0.854 to 0.570 therefore the threshold is met and all the variables are included for interpretation. For measuring performance indicators, the parameter with the high loading in each component is retained as the representative factor. Figure 2 presents the measurement model for performance indicators. 
Table 3: Eigenvalues of the correlation matrix for performance parameters

\begin{tabular}{ccrrr}
\hline Components & Eigenvalue & Difference & Proportion & Cumulative \\
\hline 1 & 9.084 & 7.054 & 0.478 & 0.478 \\
2 & 2.029 & 0.522 & 0.106 & 0.585 \\
3 & 1.506 & 0.254 & 0.079 & 0.664 \\
4 & 1.252 & 0.351 & 0.065 & 0.730 \\
\hline 5 & 0.900 & 0.109 & 0.047 & 0.777 \\
6 & 0.791 & 0.201 & 0.041 & 0.819 \\
7 & 0.589 & 0.022 & 0.031 & 0.850 \\
8 & 0.567 & 0.095 & 0.029 & 0.880 \\
9 & 0.471 & 0.127 & 0.024 & 0.905 \\
10 & 0.344 & 0.012 & 0.018 & 0.940 \\
11 & 0.332 & 0.094 & 0.017 & 0.953 \\
12 & 0.237 & 0.037 & 0.012 & 0.963 \\
13 & 0.200 & 0.011 & 0.011 & 0.973 \\
14 & 0.189 & 0.015 & 0.010 & 0.982 \\
15 & 0.173 & 0.058 & 0.009 & 0.988 \\
16 & 0.114 & 0.018 & 0.006 & 0.993 \\
17 & 0.096 & 0.032 & 0.005 & 0.997 \\
18 & 0.064 & 0.013 & 0.003 & \\
19 & 0.051 & & 0.002 & \\
\hline
\end{tabular}

Initial factor method: Principal component analysis (SAS)

Table 4: Rotated factor pattern from PCA of performance parameters

\begin{tabular}{ccccc}
\hline Variables & Factor 1 & Factor 2 & Factor 3 & Factor 4 \\
\hline PF 4c & 0.808 & & & \\
PF 4a & 0.806 & & & \\
PF 4b & 0.763 & & & \\
PF 4d & 0.757 & & & \\
PF 2a & 0.721 & & & \\
PF 3b & 0.610 & & & \\
PF 1d & & 0.749 & & \\
PF 3d & & 0.706 & & \\
PF 1c & & 0.678 & & \\
PF 3c & & 0.671 & & \\
PF 1e & & 0.510 & & \\
PF 2e & & 0.509 & & \\
PF 3a & & & 0.818 & \\
PF 1a & & & 0.731 & \\
PF 2b & & & & 0.776 \\
PF 2d & & & & \\
PF 2f & & & & \\
PF 2c & & & & \\
PF 1b & & & & \\
\hline
\end{tabular}

Rotation method: Varimax 


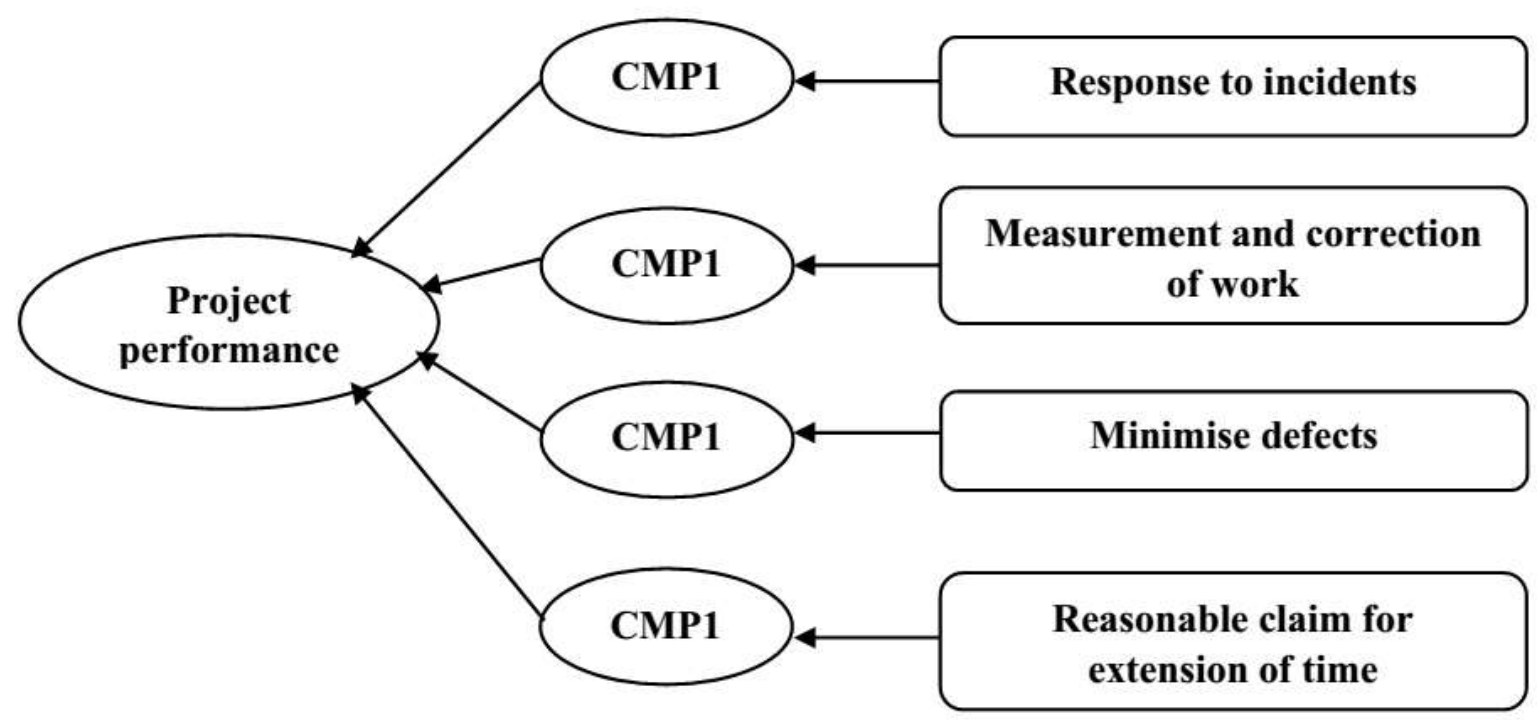

Figure 2: Measurement model for performance indicators

\subsection{Modeling for organisational incentive payoff}

This study focuses on developing multiple incentives scheme which is targeted towards incorporating the key performance metrics, namely: cost, time, quality and safety. From the PCA, four parameters are identified as the representative factors of key performance metrics. Based on the result, the metrics for measuring organisational incentive payoff are described below.

Table 5: Metrics for measuring organisational incentive payoff

\begin{tabular}{lll}
\hline KPF & Measure & Parameters \\
\hline PF1 & Cost & Measurement and correction of works \\
PF2 & Time & Reasonable claims for extension of time \\
PF3 & Quality & Minimise defects (zero defect) \\
PF4 & Safety & Response to incident rates \\
\hline
\end{tabular}

$\mathrm{KPF}=$ key performance factors; $\mathrm{PF}=$ performance factor

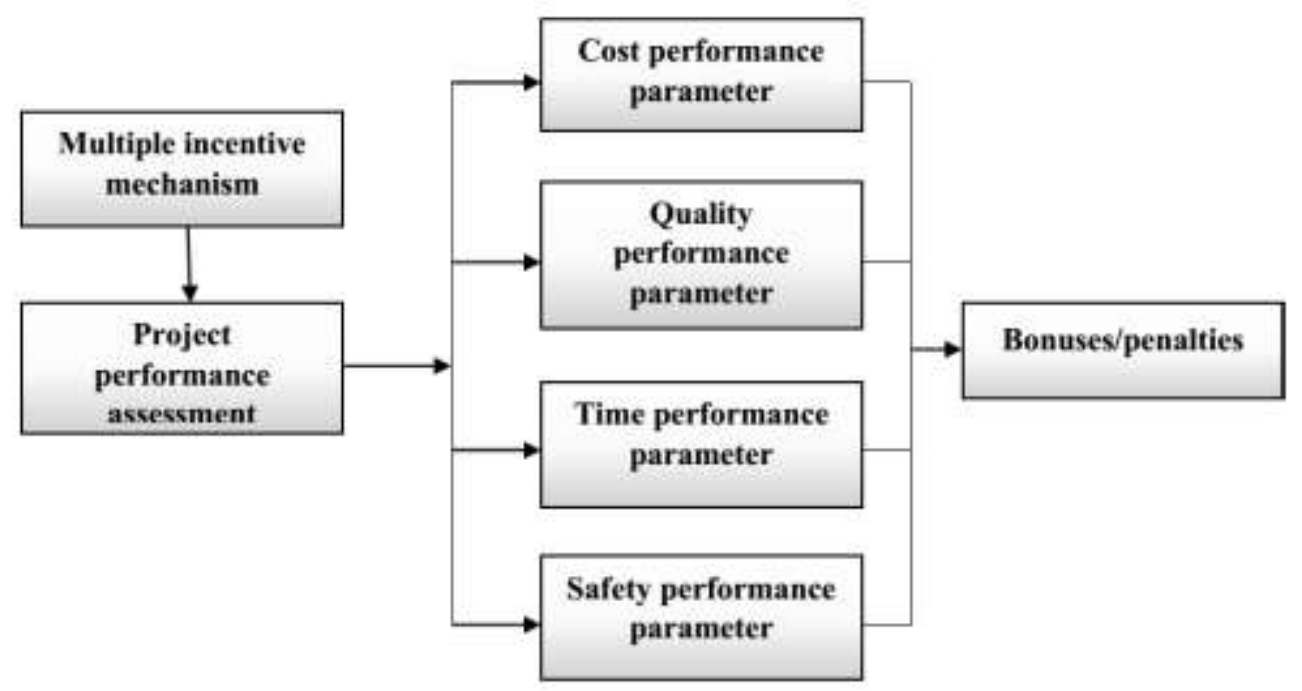

Figure 3: Organisational incentive payoff model 
The selected parameters represent the most critical factors constituting the key performance indicators in Nigerian construction projects. The following scaling factors were developed for each parameter as follows:

Measurement and correction of works:

Net value of variation $=$ Actual project cost - [Estimated project cost + Cost of change orders] - Cost of

re-work

Cost incentive payoff $=$ Net value of variation $*$ fee ratio

Note that in cost performance, if there is a positive index then multiply with the stipulated bonus sharing ratio but if it is a negative index then multiply with the stipulated penalty fee.

Reasonable claims for extension of time:

Time incentive payoff $=[$ ETPC + EOT $]-$ ATPC $=$ Index $*$ fee ratio

Where ETPC is estimated time for project completion; EOT represents extension of time granted by the client; ATPC is actual time of project completion.

Note: If there is a negative index then multiply with the stipulated penalty fee but it is a positive index then multiply with the stipulated bonus sharing ratio.

Minimise defects:

Quality incentive payoff $=$ Achieved quality rating score $*$ [Rework performed - Quality defects recorded] - Threshold value $=\operatorname{Index} *$ fee ratio

Note: The rating scale for quality measure is a seven point scale system of $1=$ very dissatisfied, $2=$ dissatisfied, $3=$ slightly dissatisfied, $4=$ neutral, $5=$ slightly satisfied, $6=$ satisfied, $7=$ very satisfied while the threshold value is 6 . Quality rating is usually measured subjectively based on the system metrics of a particular project. If there is a positive index then multiply with the stipulated bonus fee but if it is a negative index then multiply with the agreed penalty fee.

Response to incident rates:

The effectiveness of a contractor's safety efforts cannot be measured using traditional criteria. There are factors used to assess a contractor's safety efforts towards safety performance, they are as follow:

Measuring safety effort $=[$ audit score $] *$ [perception survey rating $]$

Safety incentive payoff $=$ Rating of safety efforts - Minimum acceptable level of incident rate

Note: If there is a positive index then multiply with the stipulated bonus ratio but if it is a negative index then multiply with the stipulated penalty fee ratio.

These measures provide practical formulas for assessing a contractor's ability to meet the key performance metrics incorporated in multiple incentives mechanism. As previously noted, multiple incentives contract allows for partial bonuses or losses to be awarded for each performance metric therefore it does affect the opportunity to attain other bonuses. This study did not intend to develop a single metric for overall organisational incentive payoff because it is not realistic and its application 
may not achieve the key performance measures. Therefore, it is more practical to assess these metrics separately using the formula specified for each performance metric.

\subsection{Modeling for employee incentive payoff}

Compensating employees for performance is an important tool required to enhance maximum productivity of workforce. There are two categories of workforce used for this survey which are operational workers and management staff. Figure1 presents the critical variables are used to measure employee incentive payoffs and these variables are adopted to model for operational workers in Figure 4 and for management staff in Figure 5.

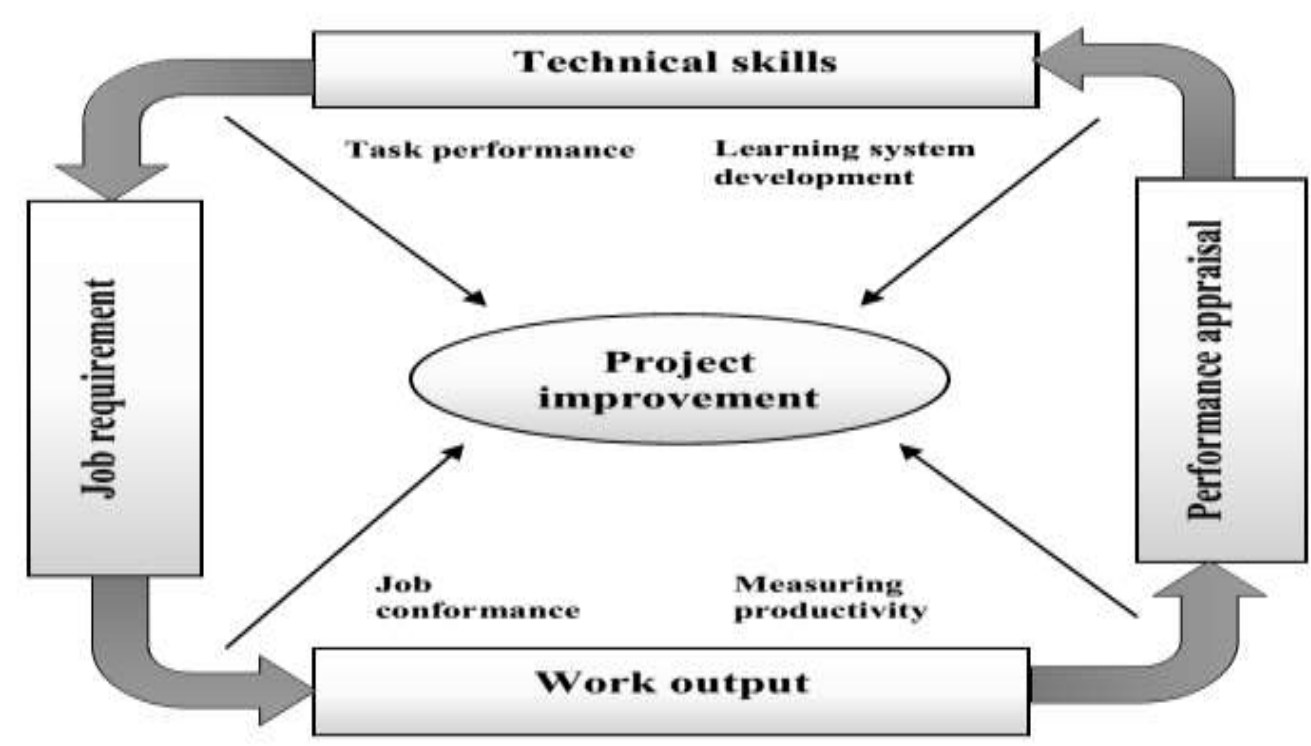

Figure 4: Employee incentive payoff model for operational workers

The reward system for an operational worker is described as follows:

Employee incentive payoff for operational worker

$\mathrm{EI}_{1}=\mathrm{f}(\mathrm{T})+\mathrm{g}(\mathrm{J})+\mathrm{h}(\mathrm{W})$

Work output $(\mathrm{W})=\mathrm{f}(\mathrm{P}-\mathrm{Q})$

Where T represents the technical ability of the worker

$\mathrm{J}$ is the job requirement

$\mathrm{W}$ represents work output of the worker

$\mathrm{P}$ is the performance of the organisation

$\mathrm{Q}$ is the performance of other employees

$f(T)$ is an increasing function of $T$

$\mathrm{g}(\mathrm{J})$ is an increasing function of $\mathbf{J}$

$\mathrm{h}(\mathrm{W})$ is an increasing function of $\mathrm{W}$ 


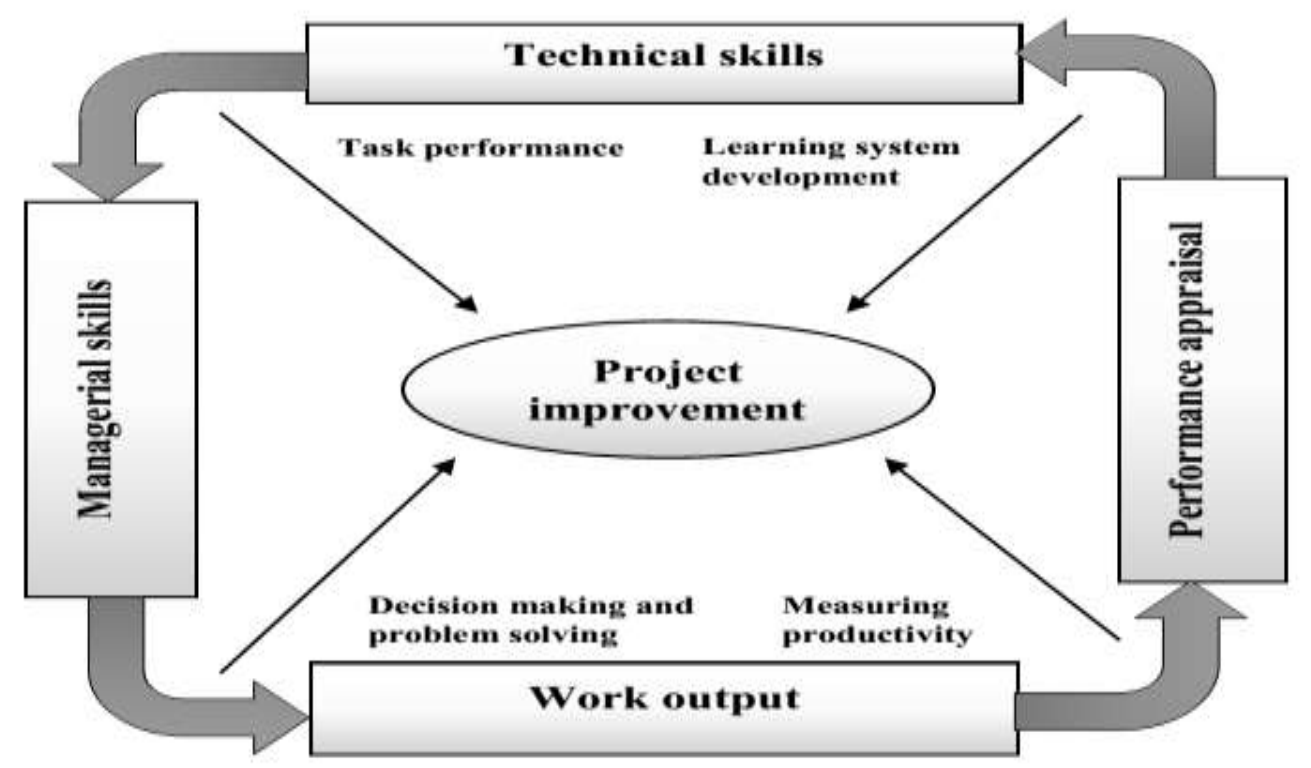

Figure 5: Employee incentive payoff model for management staff

The reward system for management staff is described as follows:

Employee incentive payoff for management staff

$\mathrm{EI}_{1}=\mathrm{f}(\mathrm{T})+\mathrm{g}(\mathrm{M})+\mathrm{h}(\mathrm{W})$

Work output $(\mathrm{W})=\mathrm{f}(\mathrm{P}-\mathrm{Q})$

Where T represents the technical ability of the worker

$\mathrm{M}$ is the managerial skills

$\mathrm{P}$ is the performance of the organisation

$\mathrm{Q}$ is the performance of other employees

W represents work output of the worker

$f(T)$ is an increasing function of $T$

$\mathrm{g}(\mathrm{M})$ is an increasing function of $\mathbf{J}$

$\mathrm{h}(\mathrm{W})$ is an increasing function of $\mathrm{W}$

\subsection{Discussions}

From the findings of variables influencing employees' compensation/incentive payoffs, "technical efforts", "work outputs" and "job requirement" were identified as the critical variables for operational workers incentive payoffs while "technical efforts", "work outputs" and "managerial skills" were identified as the critical variables for management staff incentive payoffs. This is similar with the study conducted by Bei (2013) where technical effort and work outputs were used to measure team members' productivities. In this study, technical skills are considered as critical variable for assessing both operation workers and management staff. Managers with exceptional skills are most likely to influence their projects' performances likewise operational workers require specific skills to successfully implement a specific job type. Assessing work outputs can be seen as a way of imposing disciplines required on construction workforce in order to improve productivity levels. It is important to emphasise that productivity improvements can be achieved successfully by maximising work outputs through the specified work plan thereby maintaining a predictable work flow. 
The complex nature of construction activities usually occurs due to the unique and dynamic characteristics of each project type. Mouchi et al. (2011) emphasise that the consequences of a mismatch of skills and project complexity could lead to loss of control and monumental failure in projects. Any particular project requires special skills and techniques to implement successfully therefore job requirement is highly essential in assessing the performance of a worker on site. If a worker's skill is employed for a different project type, there could be low performance due to improper mismatch of job type. Increased qualifications' levels do not necessarily render itself to improved productivity performance within the construction industry (Abdel-Wahab et al., 2008). Thus, being able to manage project activities and accommodate changes without disproportionate impact on performance necessitates a good management skill. The findings identified managerial skills as a critical variable required for assessing the performances of management staff.

The use of PCA to reduce data set for performance indicators identified the four performance parameters that influence construction projects as (1) response to incidents, (2) measurement and correction of work, (3) minimise defects, (4) reasonable claims for extension of time. An organisation's ability to respond to incidents is seen as an effective way of achieving safety performance in construction projects. In most cases, mobile clinics are situated on construction sites to aid rapid response to injuries, health conditions and other emergencies. Most respondents believe that the development of emergency plan and procedures to prevent and control further risks to employees is most essential in achieving safety performance. Change in work orders is a frequent occurrence in construction projects but when it is poorly managed, it could have a negative impact on project cost and risks. Changes can occur at different phases of a construction projects due to design changes, design errors, additions to scope, resource limitations and uniqueness of project (Yitmen et al., 2006). Most respondents believed that being able to manage change in work orders will assist to control direct costs relating to subcontractor costs, labour costs and other costs, this is in line the study conducted by Yitmen et al. (2006). Effective change management can be viewed as a cost avoidance technique and risk mitigation tactic.

Most respondents agreed that the ability to minimise defects in construction works will improve quality performance. Quality defects may be difficult to eliminate in construction projects but the concept of "zero defects" as described by Crosby (1979) emphasises that it is a way of thinking or creating a notion that defects are not acceptable. Manktelow (2015) stipulates three measures to adopt in achieving zero defects as: (a) recognise the high cost of quality issues, (b) continuously think of the places where flaws may be introduced and (c) work proactively to address the flaws in your processes which allow defects to occur. Effective management of schedule has being paramount to time performance in projects where in most cases, penalties are incorporated for time overruns. Most respondents believe that having reasonable claims of time by contractors will improve time performance.

As previously noted, there is no existing literature of incentive modelling in the Nigerian construction industry. Regardless of this, there are two existing theories of incentive modelling in the construction industry from other countries. Bei (2013) developed an incentive team-based reward model but the study failed to consider the prevailing structure of the construction sector which focused on meeting deadlines and short-term projects. Likewise, Li et al. (2003) focused on a single incentive model but failed to incorporate other aspects of performance metrics. This study identifies the critical parameters for achieving the four key project objectives which can be incorporated into the existing contractual arrangements in the Nigerian construction sector to achieve best practice in project performance. In Nigeria, traditional procurement route has remained predominant in the construction industry than other integrated routes. Dada (2012) identified the major factors contributing to the use of traditional 
procurement route as technical issues, administrative matters and personality issues. Notwithstanding, traditional procurement route has created a high level fragmentation resulting in project delays, cost and time overruns. The use of the developed organisational incentive payoff model in a traditional procurement route, as well as other integrated routes will create a good platform for clients' expectations to be achieved.

\subsection{Conclusions}

The paper investigates on how to model for incentive payoffs in the Nigerian construction industry. The study advocates the use of multiple incentives scheme where the key performance metrics such as cost, quality, time and safety are incorporated in the incentive design. The findings reveal the critical parameters measuring each performance objective and these parameters were adopted to develop a framework for organisational incentive payoff and also the scaling factors for each objective (see section 5.3). The critical variables influencing employees' efforts towards improved performance were also identified through questionnaire survey for both operational workers and management staff (see figure 1). These selected critical variables were adopted to develop the two different models for employee incentive payoffs for both operational workers and management staff (see figures 4 and 5). The study further described the reward systems for employee incentive payoff models in an organisation.

This study provides a guide on how to effectively incentivise both an organisation and its employees to achieve the key performance objectives of a construction project. The study recommends the adoption of organisational incentive payoff model in a contract agreement between the client and the contractor thereby stipulating the agreed upon fee payment ratios for bonuses and penalties based on the performance parameters. This will motivate the contractor towards improved project performance that would be of great benefits to the contracting parties. It is important to note that the driving force behind the effectiveness and efficiency of any construction firm is the human elements (workforce), therefore the adequate incentivisation of employees will contribute massively to work productivity. The two developed models for operational workers and management staff can be adopted by the contractor to improve the work productivities of his employees. The paper recommends the need to further develop user friendly application software capable of incorporating weightings of the identified performance parameters for effective usage. This study is limited to the Abuja zone of Nigeria although it could be generalised in a lesser scale to other parts of the country.

\section{References}

Abdel-Wahab, M.S., Dainty, A.R.J., Ison, S.G., Bowen, P. and Hazlehurst, G. (2008), "Trends of skills and productivity in the UK construction industry", Engineering, Construction and Architectural Management, vol. 15, no. 4, pp. 372-382.

Abdulsalam, D., Faki, A.I. \& Dardau, A.A. (2012), "Impact assessment of incentive scheme for the sustainable development of Nigerian construction industry", Journal of Civil Engineering and Architecture, vol. 6, no. 9, pp. 1194-1201.

Beer, M., Cannon, M.D., Baron, J.N., Dailey, P.R., Gerhart, B., Heneman, H.G., Kochan, T., Ledford, G.E. and Locke, E.A. (2004), "Promise and peril in implementing pay-for-performance", Human Resource Management, vol. 43, pp. 3-48.

Bei, J. (2013). The selection of incentive team-based reward model. Proceeding of 20th International Conference of Management Science and Engineering, 17-19 July, Harbin, pp. 987-992. 
Berends, T.C. (2000), "Cost plus incentive fee contracting: experiences and structuring", International Journal of Project Management, vol. 18, no. 3, pp. 165-171.

Bonner, S.E. and Sprinkle, G.B. (2002), "The effects of monetary incentives on effort and task performance: theories, evidence and a framework for research", Accounting Organizations and Society, vol. 27, no. 4-5, pp. 303-345.

Bower, D., Ashby, G., Gerald, K. and Smyk, W. (2002), "Incentive mechanism for project success", Journal of Construction Engineering and Management, vol. 18, no. 1, pp. 37-43.

Brenen, M. and Marshall, N. (2000), "Motivation, commitment and the use of incentives in partnerships and alliances", Construction Management and Economics, 18(5), pp. 587-598

Broome, J. and Perry, J. (2002), "How practitioners set share fractions in target cost contracts", International Journal of Project Management, vol. 20, pp. 59-66.

Bryson, A., Freeman, R., Lucifora, C., Pellizzari, M. and Perotin, V. (2011), Pay for performance: incentive pay schemes and employees' financial participation, Draft paper, European Science Foundation, available at http://www.cep.lse.ac.uk, retrieved on 20 April 2013.

Bubshait, A.A. (2003), "Incentive/disincentive contracts and its effects on industrial projects", International Journal of Project Management, vol. 21, no. 1, pp. 63-70.

CBP (2005), Measures of project management performance and value: a benchmark of current business practices, available at http://www.pmsolutions.com, retrieved at 4 June 2015.

Chavan, S.K. (2010), Indirect or Semi-financial incentives, available at http://www.managementparadise.com/forums/human-resources-management/201102ndirectsemi-financial-incentives.html, retrieved on 9 April 2013.

Cheung, S.O., Yiu, T.W. \& Lam, M.C. (2013), "Interweaving trust and communication with project performance", Journal of Construction Engineering and Management, vol. 139, pp. 941950.

Crosby, P.B. (1979), Quality of life, New York: McGraw-Hill books.

Dada, M.O. (2012), "Analysis of conflict centers in projects procured with traditional and integrated methods in Nigeria", Engineering, Project and Production Management Journal, 2(2), pp. 66-77.

De Silva, S. (2004), An introduction to performance and skilled-based pay systems, available at http://www.ilo.org, retrieved on April, 2013.

Department of Health and Human Resources (DHHR) (2006). Project quality management, CDC Unified process practices, available at http://www.cdc.gov, retrieved on 4 June 2015.

EHS (2001), The safety scorecard: suing multiple measures to judge safety and system effectiveness, available at http://www.ehstoday.com, retrieved on 4 June 2015.

Hosie, J. (2001), "Egan's view on contracts", Engineering Management Journal, vol. 11, no. 2, pp. 43-48. 
Hughes, W.P., Yohannes, I. and Hilling, J.B. (2007), Incentives in construction contracts: should we pay for performance? In: Proceedings of CIB world building congress: construction for development, edited by T. Haupt \& R. Milford, Cape Town, South Africa, 14-17 May 2007, pp. 2273-2283.

Incentive Research foundation (IRF), 2010. Mastering measurement: the critical performance element of incentive design, available at http://theirf.org, retrieved on 25 February 2013.

Ittnera, C. D., Larcker, D. F and Meyer, M. W (2003), "Subjectivity and the weighting of performance measures: Evidence from a balanced scorecard", The Accounting Review, vol. 78, no. 3, pp. 725-758.

Iyer, K. and Jha, K. (2005), "Factors affecting cost performance evidence from Indian construction projects", International Journal of Project Management, vol. 23, no. 4, pp. 283-295.

Jacobsson, M. and Linderoth, H.C.J. (2010), “The influence of contextual elements, actors' frames of reference and technology on the adoption and use of ICT in construction projects: a Swedish case study", Construction Management and Economics, vol. 28, no. 1, pp.13-23.

Jansson, K. and Ryddoke, R. (2010), "Quality incentive and quality outcomes in procured public transport- case study Stockholm", Research in Transportation Economics, vol. 29, pp. 1118.

Kohlmeyer, J. M and Drake, A. (2008), Risk-taking in New Project Selection: Can Bonus Incentives overcome Past Performance History? AAA 2008 MAS Meeting paper, available at Social Science Research Network, retrieved on 3 March 2013.

Kuykendall, C.J. (2007), Key factors affecting labour productivity in the construction industry, M.Sc. thesis, University of Florida, USA.

Lahdenpera, P. and Koppinen, T. (2003), Charting of incentive payment bases for multi-objective construction projects, In: Proceedings of Joint International Symposium of CIB working Commissions, Singapore, pp. 481 - 493.

Lester, A. (2007), Project management, planning and control, $5^{\text {th }}$ edition, Oxford: ButterworthHeinemann.

Li, H., Chen, Z. and Wong, C.T.C. (2003), "Barcode technology for an incentive reward program to reduce construction wastes", Computer-aided Civil and Infrastructure Engineering, vol. 18, no. 4, pp. 313-324.

Manktelow, J. (2015), Zero defects: getting it right first time, available at http://www.mindtools.com/pages/article, retrieved on 13 February 2015.

Marawar, S. (2013), "Performance appraisal system to improve construction productivity", International Journal of Scientific and Research publications, vol. 3, no. 1, pp. 1-8.

Maritz, M.J. and Ogwueleka, A.C. (2013), “Construction employees' perspectives on workforce motivational drivers in Akwa Ibom State of Nigeria", Journal of Construction, vol. 5, no. 2, pp. 2-7. 
Martin, L.L. (2003), Approaches to Performance Based Contracting (PBC) for Social Sciences, available at http://www.uky.edu, retrieved on 3 March 2012.

Martin, L.L. (2007), "Performance based contracting for Human Services: A proposed model”, Public Administration Quarterly, vol. 31, no. 2, pp. 130-158.

Meeampol, S. and Ogunlana, S.O. (2006), "Factors affecting cost and time performance on highway construction projects: evidence from Thailand", Journal of Financial management of Property and Construction, vol. 11, no. 1, pp. 3-20.

Meng, X. and Gallagher, B. (2012), "The impact of incentive mechanisms on project performance", International Journal of Project Management, vol. 30, pp. 352-362.

Mouch, G., Rotimi, J.O. and Ramachandra, T. (2011), The skill sets required for managing complex construction projects, Business Education and Accreditation, 3(1), pp. 89-100.

Neuman, W.L. (2006), Social research methods: qualitative and quantitative approaches, 6th edition, Toronto: Pearson.

OGC (2007), Project procurement lifecycle: the integrated process. Achieving Excellence Guide 3, available at http://www.webarchive.nationalarchives.gov.uk, retrieved at 20 April 2013.

Ogwueleka, A.C. (2011). The critical success factors influencing project performance in Nigeria, International Journal of Management Science and Engineering Management, 6(5), pp.343 349.

Ogwueleka, A.C. (2015), Evaluation of incentive mechanisms in performance-based contracting systems, Ph.D. thesis, Pretoria: University of Pretoria.

Olugbenga, A.O. (2011), "Performance of incentive schemes in construction projects in Nigeria", Global Journal of Management and Business Research, vol. 11, pp. 10, pp. 38-44.

Popp, L. and Zenger, T.R. (2002), "Do formal contracts and relational governance function as substitutes or complements”, Strategic Management Journal, vol. 36, no. 4, pp. 794-829.

Pournara, I. and Wernisch, L. (2007), "Factor analysis for gene regulatory networks and transcription factor activity profiles", BMC Informatics, vol. 8, no. 61, pp. 1-20.

Rose, T. and Manley, K. (2005), A conceptual framework to investigate the optimization of financial incentive mechanisms in construction projects. In: Sullivan, K.T. \& Kashiwagi, D.T. (eds.). Proceedings of CIBW92/T23 International Symposium on Procurement Systems, 8-10 February. Tempe, Arizona: Performance Based Studies Research Group, pp. 439-448.

Rose, T. and Manley, K. (2010), "Client recommendations for financial incentives on construction projects", Engineering Construction and Architectural Management, vol. 17, no. 3, pp. 252267.

Saunders, M., Lewis, P. and Thornhill, A. (2009), Research methods for business students, 5th edition, Essex, United Kingdom: Pearson Education Limited. 
Smith, D.C. and Grinker, W.J. (2003), The promise and pitfalls of Performance based contracting, Washington: APPAM, available at http://www.sedcoorg/archive/publications, retrieved on 17th March, 2012.

Tang, W., Duffield, C.F., and Young, D.M. (2006), "Partnering mechanism in construction: an empirical study on the Chinese construction industry", Journal Construction Engineering Management, vol. 132, no. 3, pp. 217-229.

Tang, W., Qiang, M., Duffield, C.F., Young, D.M., and Lu, Y. (2007), "Risk management in the Chinese construction industry", Journal Construction Engineering Management, vol. 133, no. 12 , pp. $944-956$.

Vlaar, P.W.L, Van den Bosh, F.A.J. and Volberda, H.W. (2006), "Coping with problems of understanding in inter-organizational relationships: using formalization as a means to make sense", Organization Studies, vol. 27, pp. 1617-1638.

Wang, S., Tang, W. and Li, Y. (2013), "Relationship between owners' capabilities and project performance on development of hydropower projects in China", Journal of Construction Engineering and Management, vol. 139, pp. 1168-1178.

Waris, M., Liew, M.S., Khamidi, M.F. and Idrus, A. (2014), Criteria for the selection of sustainable on-site equipment, International Journal of Sustainable Built Environment, vol. 3, no. 1, pp. 96-110.

Yamane, T. (1967), Statistics: an introductory analysis, 2nd edition. New York: Harper \& Row.

Yitmen, I., Sevay, H. and Yalciner, H. (2006), Expert system for quantifying the impact of change order in project performance, In: Joint International Conference on Computing and Decision making in Civil and Building Engineering, 14-16 June, 2006, Montreal, Canada. 